\title{
BMJ Open Between compliance and resistance: exploring discourses on family planning in Community Health Committees in Mozambique
}

\author{
Rehana Dauto Capurchande, ${ }^{1,2}$ Gily Coene, ${ }^{3}$ Kristien Roelens, ${ }^{4}$ \\ Herman Meulemans ${ }^{5,6}$
}

To cite: Capurchande RD, Coene G, Roelens K, et al. Between compliance and resistance: exploring discourses on family planning in Community Health Committees in Mozambique. BMJ Open 2015;5:e006529.

doi:10.1136/bmjopen-2014006529

- Prepublication history for this paper is available online. To view these files please visit the journal online (http://dx.doi.org/10.1136/ bmjopen-2014-006529).

Received 3 September 2014 Revised 23 April 2015 Accepted 26 April 2015
CrossMark

For numbered affiliations see end of article.

Correspondence to Dr Rehana Dauto Capurchande; rehana.dc@gmail.com

\section{ABSTRACT}

Objectives: Although the Mozambican government has implemented a community-based approach to family planning (FP), little is known about the appropriateness of this process. We explore how members of Community Health Committees (CHCs) address and act regarding FP.

Methods/settings: An in-depth qualitative study of $\mathrm{CHCs}$ was conducted at two sites in Maputo province -Ndlavela and Boane-using focus group discussions $(n=6)$, informal conversations $(n=4)$ and observation. The analysis followed a phenomenological approach.

Results: $\mathrm{CHCs}$ in Ndlavela appeared to transfer more of the expected information than those in Boane. However, in the CHCs at both study sites, we found heterogeneity in CHCs' perspectives leading to conflicting views among committee members (CMs). Arising issues included contraceptive type, target groups, the desirable number of children per family as well as the way FP was to be represented. Moreover, weak communication between CMs and health workers, and lack of payment for CMs' activities influenced promotion of FP.

Conclusions: The two CHCs framed FP in different ways leading to inconsistent participation of $\mathrm{CHC}$ members in promoting FP. Policymakers should consider the diversity of discourses and aspirations of these committees when delivering information to them.

\section{INTRODUCTION}

In Mozambique, family planning (FP) remains a public health challenge because of the low use of contraception, the uneven distribution of healthcare workers as well as the lack of accessibility of healthcare facilities across the country. ${ }^{1-5}$ In 2011, at the national level, the rate of contraceptive use by women was $11.5 \%$, which is a decrease of $2.7 \%$ from the 2003 Demographic Health Survey. In the same year, the total fertility rate was 5.9 children per woman. ${ }^{6}$

\section{Strengths and limitations of this study}

- There have been few in-depth studies exploring community-based enhancement of healthcare services in relation to family planning in Mozambique.

- Ndlavela and Boane, peri-urban and rural areas, respectively, are close to Maputo city, where the rate of contraceptive use is high and the quality of healthcare services better than the rest of the country. Committee members (CMs) from Boane may be influenced by this proximity and may not give responses typical of rural Mozambique.

- Findings from this study may provide support for theories of community-based participatory efforts. This support may be accomplished by identifying challenges and strengths to build bridges between knowledge/theory and community-based practices and policy. All this can be achieved through community engagement to decrease health disparities. The success of Community Health Committees (CHCs) in Ndlavela, in contrast to Boane, rests on a single factor. CMs in Ndlavela were more valued by health workers. This should be considered a strong strategy for improving health equity.

- There was almost a complete lack of male input in Ndlavela, as most of the male participants withdrew at the onset of the CHCs.

- This small-scale qualitative study based on focus group discussions is rather exploratory and cannot be generalised.

In order to expand access to FP services, many developing countries, including Mozambique, have implemented communitybased approaches (CBA), particularly in rural areas, where healthcare workers are scarce. $^{7-10}$ Based on the assumption that workers at the grassroots level are more accessible and acceptable to users in their communities, they are expected to improve access and coverage to basic health services. $^{911}$ 
In 1980, the Mozambican government began efforts to develop a collaborative relationship with indigenous political leaders, healers and spirit mediums concerning health issues. ${ }^{12}$ The launching of the Community Health Committees (CHCs) was part of this strategy. ${ }^{2}{ }^{13}$ Policymakers expected CHCs to collaborate with health workers and to promote the use of FP services ${ }^{2} 13$ through counselling sessions/practices. Committee members (CMs) are responsible for mobilising and counselling users/clients to use FP services. It is argued that misconceptions and fears of contraceptive side effects, particularly the intra uterine device (IUD) ${ }^{14}$ and sterilisation, contribute to discontinuation of contraceptive usage.

However, there is no consensus about how to put the CBA into practice, thus increasing the participation of all engaged in health promotion. ${ }^{815} 16$ Studies on community health workers' participation in health issues ${ }^{10} 17$ have shown that social and economic aspirations influence their motivation to get involved. Nevertheless, little is known about the way involved members interpret and conduct their daily activities. Thus, this study explores how CMs address and act regarding FP.

This study is based on a phenomenological framework $^{18}$ that stresses the importance of analysing how knowledge is produced, distributed and internalised among individuals. We focus on CMs' discourses and practices concerning FP. This perspective allows the bringing together of committee experiences as a means to grasp what is considered problematic during counselling practices.

The concept of problematic everyday life is understood here as any situation where CMs use commonsense knowledge to address challenges to FP. Since promoting FP is an interpretative practice, CMs use their knowledge to identify and sort out problems/obstacles faced during counselling sessions. This concept adds considerable explanatory power to our study by clarifying in what situations CMs may adhere successfully, what can be negotiated, and what are key obstacles interfering with FP promotion as a community-engagement policy.

This study, therefore, may possibly contribute to:

1. Understanding how CHCs implement promotion on $\mathrm{FP}$;

2. Understanding the different interpretations and perspectives of FP and the complexities involved in the triangle of health workers, CMs and clients;

3. Recommend changes to $\mathrm{CHC}$ programmes to improve their outcomes.

\section{METHODS}

\section{Setting}

This qualitative study ${ }^{19}$ was undertaken in the rural district of Boane and in Ndlavela, a neighbourhood on the outskirts of Matola city. Both sites are in Maputo province of Mozambique. Boane is located $30 \mathrm{~km}$ southwest of Maputo. With a population of $134000,{ }^{20}$ it has eight healthcare centres and three health posts. Ndlavela, located at the Administrative Post of Infulene, has a population of 57246 and one healthcare centre. ${ }^{21}$

These study sites were selected on the basis of contraceptive prevalence and geographical location. Both are located in Maputo province, which has the highest use of modern contraception in Mozambique, accounting for $32.8 \%$ among married women in $2011 .{ }^{6}$ As a result of the rural exodus, people from various regions of Mozambique mingle to create a cultural mix in both study sites.

Data were collected from February to the end of April 2013. They were based on focus group discussions (FGDs) and observation. FGDs aimed at collecting information about different perspectives and understandings about the promotion of FP. This method helped to explore aspects that often remain hidden when using conventional interviewing methods. ${ }^{192}$

This observation coincided with domiciliary visits of CHCs. Additionally, we conducted informal conversations when interacting with CMs during domiciliary visits. We understand informal conversation as a technique characterised by a total lack of structure or control. ${ }^{23}$ This method was helpful in creating sociability, as well as in understanding some CHCs' expectations and contradictory opinions in addressing FP. Data from informal interviewing were presented in summary with the results.

We also used documentary research as a means of investigation, which sustained the analysis of this study. The study reviewed and coded policy documents, specifically National Family Planning Policy, ${ }^{2}$ Health Sector Policy of 2014-2019, ${ }^{1}$ and the Terms of Reference for Implementing Committees' Health. ${ }^{13}$ As well, we conducted a literature review focusing on CBA and FP.

We applied purposive sampling. ${ }^{19}$ Six FGDs were held -three in Ndlavela and three in Boane. In total 8-10 participants were present at each of the FGDs. Each session lasted an average of $1 \frac{1}{2} \mathrm{~h}$; the sessions were moderated by the first author. Four informal conversations were held-two in Boane and two in Ndlavela, with participants of both genders.

Verbal information was provided to participants to make informed choices on whether or not to participate in this study. All participants agreed to participate in the study and signed consent forms-except those who were unable to write. For the latter participants, we read and translated the consent form into the preferred language of the participant.

\section{Data analysis}

Interviews were first transcribed, then translated (from Portuguese) to English and finally coded. From empirical codes, the study created those that were open and axial. ${ }^{24}$ Open codes consisted of highlighting what $\mathrm{CMs}$ reported as occurring more than once, what was said with intensity and aspects of behaviour that were taken for granted. Open codes encompassed knowledge, 
language, behaviour, training and misconceptions about FP. From axial codes, it was possible to created themes or categories by grouping words or phrases. These comprised labelling of disagreements/conflicts, expectations, motivations, functioning and position of CMs.

For open as well as for axial codes, we filtered, highlighted and focused on the salient features of the data recorded for generating categories and themes. From these, we were finally able to grasp meanings. Regarding coding, this process first followed the so-called 'member checking' process. This consisted of consulting the participants themselves during analysis as a way of validating the findings. Following this, double-checking and discussion proceeded.

The authors of this study were involved in various stages. Three researchers conceived this study. However, only the first researcher created a priori codes, conducted data collection in both study sites, created empirical codes and followed the member checking process. Nevertheless, almost $30 \%$ of the empirical codes were suggested by all the coauthors during the process of data analysis and discussion. The axial codes were independently verified by the second and the last researcher. All four researchers fully participated in the coding process, particularly with the double checking. The first, second and last authors wrote the text. And finally, all four researchers read and approved the final version of this article.

Data were analysed between April and July 2013, following a phenomenological approach. This framework helped to describe FP priority practices as understood by CMs. Thus, this perspective allows the researcher to include, capture and understand the CM's experiences from their perspective. Three steps were considered in the analysis: examining commonalities, differences and relationships. ${ }^{24}$

A triangulation method ${ }^{22}$ was used to discuss our data and to derive greater assurance from the findings. We cross-referenced information from FGDs, informal conversations, observation and literature review on CBA and FP, as well as the previously mentioned policy documents, explicitly the National Family Planning Policy, ${ }^{2}$ Health Sector Policy of 2014-2019 ${ }^{1}$ and the Terms of Reference for Implementation of Committees' Health. $^{13}$

\section{RESULTS}

Our findings included several different themes -composition and training, functioning of committees and diversity of positions about FP. These themes offer a possible explanation of the CHCs' role; the purpose for which it was created; the way CMs operate; their engagement; the approach used for the CHCs' implementation; and what may possibly obstruct the valued role of CHCs in implementing FP policy. We start by showing the demographic history of all participants interviewed (table 1).

\section{Composition and training of committees}

CHCs are composed of voluntary members, termed FP facilitators, who are selected at the grassroots level. At both study sites, approximately 30-40 CMs were selected by community leaders and healthcare workers based on specific criteria. These included: nomination, age, gender, residence, community leaders' recommendations and the participant's influence within the community. The following quote shows the initiative was organised top-down:

Health workers came into the community and selected 10 members (to be part of the counselling unit)...They told me that I was selected to be...a member of the committee. (Male, 67 years old, married, community leader, FGD \#03, Boane)

There were differences in terms of training the CMs received in both study sites. In Ndlavela, the nongovernmental organisation pathfinder-an international organisation working to improve sexual and reproductive health (SRH) in Mozambique-was responsible for CMs' training. This training, which lasted 3 months, consisted of providing information and strategies to promote SRH. Moreover, CMs received guidelines and equipment, such as contraceptives for demonstration. However, in Boane, CHCs were not fully trained. Instead, they were given oral instructions at the healthcare centre. CMs there only received a week of instruction consisting of general information about SRH, without any guidelines or equipment.

This is of particular interest because it demonstrates that less attention is given to training of CMs in Boane. Moreover, at both sites, education level was not considered relevant for selecting participants of CHCs. Therefore, the selected CMs were not expected to accomplish activities requiring specific skills or to perform assigned responsibilities leading to achieving worthwhile outcomes.

\section{Functioning of committees}

In Ndlavela, a clear strategy of counselling was implemented to reach schools and households. More CMs there acted according to expectation in comparison with the CHCs from Boane. However, some contradictions were generally found among CMs. Some blamed users for prejudices on particular types of contraceptives. For example, CMs reported some users believed the "IUD (Intra Uterine Device) could move from the uterus to another organ." Another misconception was: "modern contraception leads to infertility if consistently used." However, in some instances, some CMs also shared these perceptions.

The following quotation reveals the position of $\mathrm{CMs}$ who did not perpetuate mistaken beliefs and wholeheartedly recommend modern contraceptives:

We explain what family planning is and how it is done [modern contraception] and then some doubts may arise. In this case, we advise them to go to see health providers. (Female, 42 years old, married, FGD \#01, Ndlavela) 
Table 1 Demographic background of the participants

\begin{tabular}{|c|c|c|c|c|c|c|}
\hline \multirow[b]{2}{*}{ Focus group discussions } & \multicolumn{3}{|l|}{ Ndlavela } & \multicolumn{3}{|l|}{ Boane } \\
\hline & Group 1 & Group 2 & Group 3 & Group 1 & Group 2 & Group 3 \\
\hline Number of participants & 10 & 9 & 9 & 9 & 10 & 8 \\
\hline Gender (female:male) & $9: 1$ & $9: 0$ & 9:0 & $5: 4$ & $6: 4$ & $4: 4$ \\
\hline Age range (years) & $22-51$ & $24-50$ & $22-61$ & $26-78$ & $22-70$ & $34-67$ \\
\hline \multicolumn{7}{|l|}{ Educational level } \\
\hline Uneducated & 3 & 4 & 2 & 3 & 4 & 3 \\
\hline Primary school & 4 & 2 & 2 & 2 & 3 & 4 \\
\hline Secondary school & 2 & 3 & 4 & 3 & 3 & 1 \\
\hline Beyond secondary school & 1 & 0 & 1 & 1 & 0 & 0 \\
\hline \multicolumn{7}{|l|}{ Occupation } \\
\hline Activists for Mozambican women's organisations & 3 & 2 & 2 & 0 & 2 & 1 \\
\hline Community leaders & 4 & 3 & 2 & 3 & 3 & 2 \\
\hline Traditional birth attendants & 0 & 1 & 0 & 0 & 1 & 0 \\
\hline Students & 1 & 1 & 1 & 1 & 1 & 0 \\
\hline Teachers & 1 & 0 & 2 & 1 & 0 & 0 \\
\hline Healers & 0 & 1 & 2 & 0 & 0 & 1 \\
\hline Farmers & 0 & 0 & 0 & 2 & 2 & 2 \\
\hline Informal sellers & 1 & 1 & 0 & 1 & 0 & 1 \\
\hline Waitresses & 0 & 0 & 0 & 1 & 0 & 0 \\
\hline Traditional leaders & 0 & 0 & 0 & 0 & 1 & 1 \\
\hline
\end{tabular}

Many CMs did not agree on which contraceptive methods should be used. While some members in Ndlavela recommended "it's important to use modern contraception," others in Boane asserted "traditional contraceptives (indigenous contraceptives based on traditional local practices) were used by the ancestors and are effective".

Indigenous contraceptives consist of herbs, amulets and charms believed to prevent pregnancy. For example, CMs reported an indigenous method entailing preparing the pad used on the first day of menstruation with plants and a stuffed snail's carcass, and placing it in a closed place or burying it.

In both study sites, CMs who were committed to promote modern contraception largely favoured disseminating information about injections, pills and condoms. However, almost all CMs avoided promoting sterilisation and IUDs. This was due to precepts and beliefs users and some CMs had about them. The topic of sterilisation was not even broached because many think "sterilisation means it takes away a woman's essence". Some CMs feared the IUD would come out of the cervix itself. Others were uncomfortable with the idea that "men can touch the IUD during sexual intercourse":

The IUD...if you introduce fingers, you can touch and feel it. So how can you hide it from your husband? How to talk about it with users? (Female, 41 years old, married, OMM, FGD \#03, Ndlavela)

From this quote, it is clear that the functioning of CHCs can be threatened by differences in knowledge, sociobackground and misconceptions about contraceptives shared among CMs. Misconceptions about IUDs and sterilisation are rooted in community norms and beliefs about contraceptives.

The relationship between CMs and health workers was slightly more delicate in Boane than in Ndlavela. In Ndlavela, some regular meetings with health workers were held for reporting the CMs' activities and, when necessary, or receiving instructions. However, in Boane, most participants stated health workers did not take the committee's work seriously:

They (health workers) do not even recognise us because we are not providers. (Female, 45 years old, married, TBA, \#02, Boane)

In both study sites, findings also revealed most CMs were less motivated because it was unpaid work:

If this work was paid, it would motivate members of [the] committee to cover a wide range of users. (Female, 43 years old, OMM, \#02, Ndavela)

As demonstrated by the two previous quotes, it is clear that both motivational factors-recognition from health workers and no monetary incentive for CMs-influenced their performance and their enthusiasm or lack of it, to remain CMs. Most CMs have poor economic status and a low standing in comparison with professional health workers. Thus, respect from health workers could/would reinforce retention of CMs. Such recognition of CMs by health workers would enhance their identity in their communities because they are carrying out an important role. 


\section{Diversity of positions about FP}

In both study sites, we observed disagreements about the counselling target group. While some CMs defined adolescents as a target group, others identified a target group to be adults of reproductive age or older:

Above 18 years, the decision not to have children...it doesn't make any sense. But today, girls aged 10 to 12 have already had sexual intercourse. The FP target should be people from 10 to 15 ...because they are already discovering the world. (Female, 52 years old, married, community leader, FGD \#02, Boane)

In Ndlavela and Boane, there was no agreement among CMs on the number of children a couple should have CMs adhering to the health guidelines suggested five children. This differed from the much higher number many CMs felt was appropriate. However, female CMs were less likely to promote more than five children.

Differences between female and male CMs regarding family size may be associated with the fact that men more often dominate decision-making when it comes to FP. Moreover, the CMs who advise more than five children explain their position as a guarantee for a family's subsistence. Children are the workforce on a farm, and guarantee their parents' social assistance when they are old. Large families also preserve the kin and maintain the husband's 'manhood' identity.

In Ndlavela, most participants accused the government of not having a clear strategy to increase men's participation in contraception. However, in Boane, most CMs believed the government was responsible for the unclear strategy dealing with the generational conflict, as well as for their own decreasing power.

I said in the beginning that the Government should give back some power to us. If that doesn't happen, we can't solve the matters of FP. This can't be said in words but on paper. (Male, 50 years old, married, community leader, FGD \#01, Boane)

CMs' symptoms revolve around two points. First, the top-down initiative makes many CMs feel their decisionmaking power is decreasing on issues related to their communities. Second, FP clients are reluctant to change their behaviour. This is particularly true of adolescents who are of the opinion that a lack of strategy impedes better implementation of FP initiatives.

\section{DISCUSSION}

This study reveals how FP promotion as a communityengagement policy can be derailed by inadequate attention to who is responsible to disseminate the information, cultural differences, diversity of knowledge, quality of training, engagement of CMs and socioeconomic aspirations. This is in-line with studies showing that insufficient attention to issues, such as quality of training and monetary incentives lead, over time, to decreasing usefulness of programmes. ${ }^{7} 1725$ Using a community-engagement policy can be effective in improving access and coverage to basic health services, especially when taking into account organisational (training and supervision), economic and sociocultural factors. .7625

In fact, in Ndlavela, there was a stronger trend towards pursuing the CHCs' role than in Boane. These differences can be associated with training, sociocultural background, differences in knowledge as well as geographical location. In Boane, CHCs received only brief instructions. Boane is located in rural Mozambique. In Boane, the average fertility rate is 6.6 children per woman and the use of modern contraception is $7 \% .^{6}$ Its inhabitants are more deeply influenced by traditional, social and religious norms, ${ }^{3}$ and the marital age for girls is $12 .^{20}$

There are considerable differences between CHCs in Ndlavela and Boane. However, the CHC's role in promoting FP in both study sites may be threatened by the top-down initiative and heterogeneity of the CM's perspectives. Respectively, these include the perception of decreasing power in implementing FP policy as well as gender differences between and intra-CHCs in relation to FP topics.

All these issues influence the commitment of CMs, ultimately leading to their inconsistent participation. These findings are congruent with other studies, where outcomes of CBA vary because communities or CHCs are partially involved in priority setting, resource allocation, implementation and cultural background. ${ }^{826}$ As Rifkin highlights, ${ }^{15}$ the lack of agreement about how to better develop community participation in order to gain expected benefits interferes with health outcomes.

In Mozambique, policymakers put forward CHCs not as substitutes for professional health workers but as complementary to service delivery. ${ }^{12}{ }^{13}$ However, there were some gaps in the relationship among CHCs, policymakers, health workers and clients. For the CMs, it all depended on which group was considered to be problematic in delivering FP. The health workers' style of communication was seen as problematic, and policymakers were held responsible for the lack of a clear strategy to increase men's participation in FP. As well, some CMs' and clients' beliefs and/or reluctance towards IUDs and sterilisation were seen as problematic. This last drawback is consistent with studies showing fears of side effects and misconceptions of IUD and sterilisation as obstacles for contraceptive use. These consist of bleeding, fear of infertility, pelvic pain and cultural norms against sterilisation. ${ }^{14}{ }^{27}$ Misinformation, shared among CMs may hamper their effectiveness in helping clients to discriminate between real and imaginary contraceptive side effects.

Differences between Ndlavela and Boane, in terms of success of FP policy implementation, may provide possible support for theories about community-based participatory efforts. This may be carried out by identifying challenges, strengths and barriers to building bridges 
between knowledge/theory, and community-based practices and policy, through community engagement, to decrease health disparities. ${ }^{28}$

Barriers/challenges, when disclosed and addressed through a CBA, can lead to building programmes and community members' involvement. The success of CHCs in Ndlavela is an excellent illustration. There, CMs were valued more highly by health workers. This was demonstrated by postponing regular meetings when necessary and recognising their part in the overall work. As well, their expectations and voices were heard. Therefore, this might be considered as indicative of a strong strategy for developing and improving the local population's health status. As argued by several researchers, ${ }^{28}$ community-based participatory research is an approach that combines knowledge and social action to achieve social change, to improve community health and eliminate health disparities.

This small-scale qualitative study has limitations, primarily due to disadvantages associated with FGDs. ${ }^{19} 22$ FGDs were held with several people at one time. This resulted in gaining less information from each individual participant. However, all respondents expressed themselves adequately because we had developed an effective way to restrain more talkative participants and encourage less forward participants to speak. This was accomplished in a manner that did not influence anyone present.

However, this study has some policy implications. First, in order to ensure quality of care delivery, there is a need to pay attention to organisational issues-training and supervision-as well as motivational factors-forms of CMs' reward and recognition. Second, there is a need for disseminating accurate information about sterilisation and IUD usage. Third, it is important to encourage male participation in FP and strengthen the relationship between CMs and health workers. Lastly, more research is needed for examining factors that enhance the sustainability of CHCs to implement FP policy in Mozambique.

\section{Author affiliations \\ ${ }^{1}$ Department of Sociology, Eduardo Mondlane University, Maputo, Mozambique \\ ${ }^{2}$ Vrije Universiteit Brussel (Brussels University), Centre for Research in Gender and Diversity, Brussels, Belgium \\ ${ }^{3}$ Department of Philosophy and Ethics, Vrije Universiteit Brussel (Brussels University), Centre for Research in Gender and Diversity, Brussels, Belgium ${ }^{4}$ Department of Obstetrics and Gynecology, Universiteit Gent (Ghent University), Ghent, Belgium \\ ${ }^{5}$ Department of Sociology, Universiteit Antwerpen (Antwerp University), Centre for Longitudinal and Life Course Studies, Antwerpen, Belgium \\ ${ }^{6}$ Centre for Health Systems Research and Development (CHSR\&D), University of the Free State, Bloemfontein, South Africa}

Acknowledgements The authors would like to thank Professor Elísio Macamo, Professor Esmeralda Mariano, Professor Diederike Geelhoed and Neal McKenna for their suggestions.

Contributors RDC is the main researcher and conceived the study, and contributed to the data analysis and writing process. GC conceived of the study, the data analysis and writing process. KR contributed to the data analysis. HM contributed to formulation of the study, data analysis and writing. All authors read and approved the final manuscripts.
Funding Funding for the work undertaken in this manuscript was provided by a project grant from the Desafio, Development Programme in Reproductive Health; HIV/AIDS and Family Matters; Eduardo Mondlane University, Mozambique; and the Flemish Interuniversity Council (VLIR)

Competing interests None declared.

Patient consent Obtained.

Ethics approval Ethical approval was granted by the Mozambican National Bioethical Committee for Health (504/GMS/002/2013).

Provenance and peer review Not commissioned; externally peer reviewed.

Data sharing statement No additional data are available.

Open Access This is an Open Access article distributed in accordance with the Creative Commons Attribution Non Commercial (CC BY-NC 4.0) license, which permits others to distribute, remix, adapt, build upon this work noncommercially, and license their derivative works on different terms, provided the original work is properly cited and the use is non-commercial. See: http:// creativecommons.org/licenses/by-nc/4.0/

\section{REFERENCES}

1. MISAU. Plano estratégico do sector saúde: 2014-2019. Maputo, Moçambique: MISAU, 2014.

2. MISAU. Estratégia do planeamento familiar. Maputo, Moçambique: MISAU, 2010.

3. Agadjanian V. Religious denomination, religious involvement, and modern contraceptive use in Southern Mozambique. Stud Fam Plan 2013;4:259-74.

4. Yao J, Murray AT, Agadjanian V, et al. Geographic influences on sexual and reproductive health service utilization in rural Mozambique. Appl Geogr 2012;32:601-7.

5. Prata N, Sreenivas A, Bellows B. Potential of dual use policies to meet family planning and HIV prevention needs: a case study of Zimbabwe and Mozambique. J Fam Plann Reprod Health Care 2008;34:219-26.

6. INE and MISAU. Moçambique, inquérito demográfico e de saúde 2011. Maputo, 2013.

7. Abbot A, Luke N. Local hierarchies and distributor (non) compliance: a case study of community-based distribution in rural north India. Health Care Women Int 2011;32:225-42.

8. Mubyazi GM, Hutton G. Rhetoric and reality of community participation in health planning, resource allocation and service delivery: a review of the reviews, primary publications and grey literature. Rwanda J Health Sci 2012;1:51-6.

9. Chin-Quee D, Bratt J, Malkin M, et al. Building on safety, feasibility, and acceptability: the impact and cost of community health worker provision of injectable contraception. Glob Health Sci Pract 2013;1:316-27.

10. Maes K, Kalofonos I. Becoming and remaining community health workers: perspectives from Ethiopia and Mozambique. Soc Sci Med 2013;87:52-9.

11. Wallerstein NB, Duran B. Using community-based participatory research to address health disparities. Health Promot Pract 2006:7:312-23.

12. Chapmann RR. Family secrets: risking reproduction in Central Mozambique. Nashville: Vanderbilt University Press, 2010.

13. MISAU. Termos de referência para o estabelecimento e funcionamento dos comités de saúde. Maputo, Moçambique: MISAU, 2012

14. Alnakash AH. Influence of IUD perceptions on method discontinuation. Contraception 2008;78:290-3.

15. Rifkin S. Lessons from community participation in health programmes: a review of the post Alma-Ata experience. Int Health 2009;1:31-6.

16. Laverack G, Wallerstein N. Measuring community empowerment: a fresh look at organizational domains. Health Prom Int 2001:16:179-85.

17. Takasugi T, Lee ACK. Why do community health workers volunteer? A qualitative study in Kenya. Public Health 2012;126:839-45.

18. Berger P, Luckmann T. The social construction of reality. London: Penguin Books, 1966.

19. Yin RK. Qualitative research from start to finish. New York: Guildford Press, 2011.

20. MAE. Perfil do distrito de Boane. Maputo: Ministério da Administração Estatal, 2012. 
21. CMCM. Lista da densidade. posto administrativo municipal do Infulene. Conselho Municipal da Cidade de Matola, 2013.

22. Bryman A. Social research methods. Oxford: University Press, 2004.

23. Bernard $\mathrm{RH}$. Research methods in anthropology: qualitative and quantitative approach. 4th edn. Lanham: AltaMira Press, 2006.

24. Gibson W, Brown A. Working with qualitative data. London: Sage Publications, 2009.

25. Hermann K, Damme WV, Pariyo GW, et al. Community health workers for ART in sub-Saharan Africa: learning from experience-capitalizing on new opportunities. BioMed Central 2009;7:31.
26. Phillips JF, Greene WL, Jackson EF. Lessons from community-based distribution of family planning in Africa. Policy Research Division, 1999. (Working Papers).

27. Kassa M, Abajobir AA, Gedefaw $\mathrm{M}$. Level of male involvement and associated factors in family planning services utilization among married men in Debremarkos town, Northwest Ethiopia. BMC Int Health Hum Rights 2014;14:33.

28. Wallerstein N, Duran B. Community-based participatory research contributions to intervention research: the intervention of science and practice to improve health equity. Am J Public Health 2010;100 (Suppl 1):S40-6. 